\title{
Time Series Behavior of the Volume of Wood Products Export in Ghana
}

\author{
Stella B. Acquah ${ }^{1}$, Richard K. Avuglah ${ }^{2} \&$ Emmanuel Harris $^{2}$ \\ ${ }^{1}$ CSIR-Forestry Research Institute of Ghana, University Post Office Box 63, KNUST, Kumasi, Ghana \\ ${ }^{2}$ Department of Mathematics, Kwame Nkrumah University of Science and Technology Kumasi, Ghana \\ Correspondence: Stella B. Acquah, CSIR-Forestry Research Institute of Ghana, University Post Office Box 63, \\ KNUST, Kumasi, Ghana. E-mail: s_britwum@yahoo.com/sbritwum@csir-forig.org.gh
}

Received: June 20, 2014 Accepted: July 24, 2014 Online Published: August 14, 2014

doi:10.5539/ijsp.v3n4p12ＵRL: http://dx.doi.org/10.5539/ijsp.v3n4p12

\begin{abstract}
This study examines the patterns in the export of wood products in Ghana from 1997-2013. We also build a time series model to forecast the volume of wood products export over the same period. The study employs the Box-Jenkins methodology of building ARIMA (Autoregressive Integrated Moving Average) model. Monthly time series data on exports of wood products from 1997-2013 were extracted from monthly and annual reports on export of wood products published by the Timber Industry Development Division (TIDD) of the Forestry Commission of Ghana. Different selected models were tested to ensure the accuracy of obtained results and ARIMA $(3,1,0)(0$, $1,1)_{12}$ was adjudged the best model. This model was then used to forecast the volume of wood products export for 2014 and 2015. January and June represent the minimum and maximum export periods respectively. The model will guide TIDD in their annual timber export planning and also help avoid financial losses that could result from poor decision making and ultimately improve efficiency of their operations.
\end{abstract}

Keywords: Autoregressive Integrated Moving Average (ARIMA), forecasting, forestry sector, time series, wood products

\section{Introduction}

The forestry sector plays an important role in the Ghanaian economy. Its contribution to Gross Domestic Product (GDP) increased from 2.5\% in 1991 to 8\% in 1997 (Oduro, Duah-Gyamfi, Acquah, \& Agyeman, 2012). However, due to the dwindling forest resource base, the sector's contribution to GDP reduced to 4\% in 2009 (Oduro et al., 2012). The timber industry is the fourth largest foreign exchange earner after minerals, cocoa and oil exports (Forest Investment Plan (FIP), 2012; Owusu, 2001). Timber export earned Ghana around 10\% of the foreign exchange between 1990 and 2000 but there has been a considerable decline since 2005 from $8.1 \%$ to about $1.3 \%$ in 2011 (FIP, 2012). This decline has been attributed to ongoing dwindling natural tropical forest resource base, low production recovery rates, wood wastes and illegal chainsaw activities (Oduro, Mohren, Affum-Baffoe, \& Kyereh, 2014; Hansen, Damnyag, Obiri, \& Carlsen, 2012; Marfo, 2010; Food and Agriculture Organization (FAO), 2005; Forestry Outlook Study for Africa (FOSA), 2001). Ghana's original forest cover of 8.2 million hectares has decreased to an estimated 1.6 million hectares by the year 2010 (FIP, 2012). According to FAO (2010), deforestation rate in Ghana has been around 2\% per annum for the period between 1990 and 2010, leading to an annual loss of about 135,000 hectares. The decline in the forest resources has resulted in major consequences for the timber industry. For example, about 60 local timber companies out of 200 processing mills have collapsed in the last 10 years, leading to the loss of about 30,000 jobs. Companies that had managed to survive the turbulence in the industry are currently producing below 50 per cent capacity (Daily Guide, 2012).

The Government of Ghana has instituted a number of interventions in the forestry sector aimed at sustainable management and use of timber resources. In spite of these interventions, the volume of wood products export is still declining resulting in reduced export earnings. In 2011, Ghana earned about 107.4 million Euros from the export of $319842 \mathrm{~m}^{3}$ of wood products. In 2012 however, total export volume of wood products declined to 251346 $\mathrm{m}^{3}$ valued at 99.8 million Euros, showing a decrease of $21.4 \%$ in volume and $7.1 \%$ in earnings (Timber Industry Development Division (TIDD), 2012). The situation is compounded by increased domestic demand which has 
resulted in high illegal timber extraction. This imbalance of the demand and supply of timber is among the major reasons for the current unsustainable use of the forest resources in Ghana. These challenges have raised concerns about Ghana's ability to meet the future demand of wood products export to the international market, since the international demand continues to increase. In the past, Ghana's share of global tropical wood export has been about 2.2\% (FOSA, 2001). The international demand for wood products is however expected to increase following historical trends. Traditionally, Europe and United States have been the main markets for Ghana's wood products. Emerging markets in Asia and the Far East now include India, Malaysia, Taiwan, China, Singapore, and Thailand. This raises the question of what the future export demand for Ghana's wood products will be. Will Ghana be able to meet the future export demand for wood products? This paper seeks to examine the patterns in wood products export from Ghana over the past 17 years and to use that to predict the volume of wood products export in 2014 and 2015. It is anticipated that the volume of wood products export from Ghana would increase in response to the increasing demand from the International and emerging markets.

The paper consists of four (4) sections. In the first section the background to the study is discussed and the objectives explicitly stated. Section 2 presents the Box-Jenkins modeling building methodology used for the study. Results and discussion of the performance of wood products export as well as how ARIMA models have been adapted for the export of wood products and forecasting are presented in Section 3. In the final section, conclusion is presented.

\section{Method}

\subsection{Box-Jenkins Modeling Methodology}

The Box-Jenkins three stage iterative modeling methodology was utilized to fit a seasonal ARIMA model and to forecast the volume of wood products export. ARIMA approach combines an autoregressive process and a moving average process. An autoregressive model uses the statistical properties of the past behavior of a variable to predict its behavior in the future. An autoregressive model of order $p$, denoted by $\operatorname{AR}_{(p)}$ is given as

$$
Y_{t}=\mu+\phi_{1} Y_{t-1}+\phi_{2} Y_{t-2}+\ldots+\phi_{p} Y_{t-p}+\varepsilon_{t}
$$

$\varepsilon_{t}$ is defined as a White Noise (WN) process if $\left\{\varepsilon_{t}\right\}$ is a sequence of independently and identically distributed with mean zero, finite variance, $\sigma^{2}$ and no correlation between its values at different times. $\mu$ is the expectation of $Y_{t}$ (often assumed to be equal to 0). From Equation (1), $\varepsilon_{t}$ is assumed be white noise. $\phi_{1}, \phi_{2}, \ldots \phi_{p}$ are unknown parameters relating $Y_{t}$ to $Y_{t-1}, Y_{t-2}, \ldots Y_{t-p}$ and are estimated from sample data. Moving average regresses the current $Y_{t}$ on the past random errors that occurred in past time periods, $\varepsilon_{t-1}, \varepsilon_{t-2, \ldots}, \ldots \varepsilon_{t-p}$. A moving average of order $q$, denoted by $\mathrm{MA}_{(q)}$ is given as

$$
Y_{t}=\mu+\varepsilon_{t}+\theta_{1} \varepsilon_{t-1}+\theta_{2} \varepsilon_{t-2}+\ldots+\theta_{q} \varepsilon_{t-q}
$$

where the $\theta_{1}, \ldots \theta_{q}$ are the parameters of the model, $\mu$ is the expectation of $Y_{t}$, and the $\varepsilon_{t}, \varepsilon_{t-1}, \ldots \varepsilon_{t-q}$ are again, assumed to be white noise (Gershenfeld, 1999; Shumway, 1988). To create an ARMA model, the two Equations (1 and 2) are combined to give Equation (3).

$$
Y_{t}=\mu+\phi_{1} Y_{t-1}+\phi_{2} Y_{t-2}+\ldots+\phi_{p} Y_{t-p}+\varepsilon_{t}+\theta_{1} \varepsilon_{t-1}+\theta_{2} \varepsilon_{t-2}+\ldots+\theta_{q} \varepsilon_{t-q}
$$

An autoregressive integrated moving average (ARIMA) model is a generalization of an autoregressive moving average (ARMA) model. The model is generally referred to as an ARIMA(p, d, q) model, where $p, d$ and $q$ are integers greater than or equal to zero. The first parameter, $p$ refers to the number of autoregressive lags, the second parameter, $d$ refers to the order of integration, and the third parameter, $q$ gives the number of moving average lags. In general, the model can be written as

$$
\phi(B)(1-B)^{d} x_{t}=\theta(B) w_{t}
$$

where $\left\{w_{t}\right\} \sim W N\left(0, \sigma^{2}\right)$. The lag or backshift operator denoted by $B$ shifts a time series so that the shifted time series lags one time unit behind. The backshift operator B is defined by $B^{k} x_{t}=x_{t-k}$ and the autoregressive and moving average operator are defined as follows:

$$
\begin{gathered}
\phi(B)=1-\phi_{1} B-\phi_{2} B^{2}-\ldots-\phi_{p} B^{p} \\
\theta(B)=1+\theta_{1} B+\theta_{2} B^{2}+\ldots+\theta_{q} B^{q}
\end{gathered}
$$


$\phi(B) \neq 0$ for $|B| \leq 1$, the process $\left\{x_{t}\right\}$ is stationary if and only if $d=0$, in which case it reduces to an ARMA(p, q) process. An $\operatorname{ARMA}(\mathrm{p}, \mathrm{q})$ model is stationary if $\phi(B) \neq 0$ for $|B| \leq 1$. The $\operatorname{ARMA}(\mathrm{p}, \mathrm{q})$ is also invertible if $\theta(B) \neq$ 0 when $|B| \leq 1$ or when the roots of $\theta(B)$ lie outside the unit circle.

Multipicative Seasornal ARIMA model (SARIMA) is a modification to the ARIMA model because of seasonal and non-stationary behavior. The volume of wood products export data showed a yearly seasonal component at seasonal level 12. The pure seasonal ARMA model, denoted by $\operatorname{ARMA}(\mathrm{P}, \mathrm{Q})$ takes the form:

$$
\Phi_{p}\left(B^{S}\right) x_{t}=\Theta_{Q}\left(B^{s}\right) w_{t}
$$

The seasonal autoregressive operator and the seasonal moving average operator of orders $P$ and $Q$ with seasonal periods are given respectively as follows:

$$
\begin{aligned}
& \Phi_{P}\left(B^{s}\right)=1-\Phi_{1} B^{s}-\Phi_{2} B^{2 s}-\ldots-\Phi_{p} B^{p s} \\
& \Theta_{Q}\left(B^{s}\right)=1+\Theta_{1} B^{s}+\Theta_{2} B^{2 s}+\ldots+\Theta_{Q} B^{Q s}
\end{aligned}
$$

In general, we can combine the seasonal and non-seasonal operators into a multiplicative seasonal autoregressive moving average model, denoted by $\operatorname{ARMA}(\mathrm{p}, \mathrm{q}) \times(\mathrm{P}, \mathrm{Q})_{s}$ and write

$$
\Phi_{P}\left(B^{s}\right) \phi(B) x_{t}=\Theta_{Q}\left(B^{s}\right) \theta(B) w_{t}
$$

as the overall model.

The multiplicative seasonal autoregressive integrated moving average model, or SARIMA model of Box and Jenkins (1970) is given by

$$
\Phi_{P}\left(B^{s}\right) \phi(B) \nabla_{s}^{D} \nabla^{d} x_{t}=\alpha+\Theta_{Q}\left(B^{s}\right) \theta(B) w_{t}
$$

where $w_{t}$ is the causal Gaussian white noise process. The general model is denoted by $\operatorname{ARIMA}(\mathrm{p}, \mathrm{d}, \mathrm{q}) \times(\mathrm{P}, \mathrm{D}$, $\mathrm{Q})_{s}$. The ordinary autoregressive and moving average components are represented by polynomials $\phi(B)$ and $\theta(B)$ of orders $p$ and $q$ respectively and the seasonal autoregressive and moving average components by polynomials $\Phi_{P}\left(B^{s}\right)$ and $\Theta_{Q}\left(B^{s}\right)$ of orders $P$ and $Q$ and ordinary and seasonal difference by:

$$
\nabla^{d}=(1-B)^{d} \text { and } \nabla_{s}^{D}=\left(1-B^{s}\right)^{D}
$$

Generally, the Box-Jenkins method consists of three steps. The first step is model identification. In this stage, the order of autoregressive, integration and moving average (p, d, q) of the ARIMA model are determined. This can be done by looking at plots of the autocorrelation function (ACF) and partial autocorrelation function (PACF) which are the most important elements of time series analysis and forecasting. The second stage is estimation of parameters. This is concerned with assigning numerical values to the $\phi$ and $\theta$ coefficients. The maximum likelihood estimation or non-linear least-squares estimation methods can be used. Estimation of parameters of MA and ARMA models usually requires a more complicated iteration procedure (Box \& Jenkins, 1970; Chatfield, 2004). The third stage is diagnostic checking and forecasting. Once the model has been identified and the parameters estimated, the diagnostic checking stage attempts to judge whether the model as identified and estimated is indeed an appropriate data generating process. This overall adequacy can be judged by testing the estimated residuals for "whiteness" or independence. This is usually done by correlation analysis through the residual ACF plots and the goodness-of-fit test by means of Chi-square statistics $\left(\chi^{2}\right)$. The Ljung and Box test for whiteness of the residuals can also be applied. If the residuals turn out to be white noise, then one accepts the particular fit and then forecast values of the time series; otherwise, the Box-Jenkins three step iterative process is repeated until a satisfactory model is obtained.

\subsection{Stationary Time Series}

Before the Box-Jenkins methodology can be applied, one basic assumption has to be fulfilled. The time series values must be stationary where its mean and variance are constant through time. The constant mean and variance can be achieved by removing the pattern caused by the time dependent autocorrelation. Besides looking at the plot of the time series values over time to determine stationary or non-stationary, the sample autocorrelation function (ACF) also gives visibility to the data. If the ACF of the time series values either cuts off or dies down fairly quickly then the time series values should be considered stationary. On the other hand, if the ACF of the time series values either cuts off or dies down extremely slowly, then it should be considered non-stationary. In general, 
if the original time series values are non-stationary and non-seasonal, the first or second differencing transformation on the original data will usually produce stationary time series values. Also, the log transformation approach may be applied to time series with unstable variance.

Additionally, a unit root test provides a more formal approach in determining the degree of differencing such as Kwiatkowski-Phillips-Schmidt-Shin (KPSS) and the Augmented Dickey-Fuller (ADF) Unit Root Tests. The Kwiatkowski-Phillips-Schmidt-Shin (KPSS) test for the null hypothesis of a level or trend stationary against an alternative of unit root together with the ADF test for the null hypothesis of a unit root against the alternative of a stationary series. For the KPSS, the decision rule is that, if the $p$-value of the test statistic is less than the critical value of say 0.05 , then reject the null hypothesis of having a level stationary series and conclude that the alternate hypothesis has a unit root. The ADF test on the other hand tests for the null hypothesis of unit root against an alternative hypothesis of a stationary series by rejecting the null hypothesis if its $p$-value is less than the critical value chosen.

\section{Results and Discussion}

\subsection{Data}

Two hundred and four (204) monthly data on the volume $\left(\mathrm{m}^{3}\right)$ and value (Euros) of wood products export from January 1997 to December 2013 were obtained from the monthly and annual reports on export of wood products by the Timber Industry Development Division (TIDD) of the Forestry Commission of Ghana. Primary data was also obtained through personal communication with the research and statistics unit of TIDD. TIDD is the responsible agency which compiles data on export of wood products. The time series data was first decomposed in order to consider the types of data patterns so that the models most appropriate to the patterns could be utilized. The decomposition revealed trends, seasonal variations and irregular patterns. Based on the inspection of the decomposition plot, we considered fitting a seasonal ARIMA model to the data. The data was also examined to look at patterns in the wood products export sector. The R statistical package version 3.0.2 and Microsoft Excel 2007 was used for the analysis.

\subsection{Performance of Wood Products}

The export of wood products over the period 1997-2013 shows a quadratic trend (Figure 1). The volume of wood products exported increased gradually from 1997 reaching a maximum point in 2008 and then declined steeply from 2009 to 2013. Various factors may account for the downward trend. These include the global concern for the trade in illegal timber and the rapid decline in the forest resource base as a result of agricultural expansion and illegal logging (Adam, 2002; Citifmonline, 2010; Ghana-RPP., 2010). 2012 and 2008 experienced the lowest (251 $245.61 \mathrm{~m}^{3}$ ) and highest $\left(545915.08 \mathrm{~m}^{3}\right)$ export volumes respectively whilst 2012 and 2000 accounted for the lowest (99.84 million Euros) and highest (210.3 million Euros) export earnings respectively. The highest volume of wood products export was in 2008 but due to high volume of primary products the total earnings was not the highest for that year. Value addition through secondary and tertiary processing increased the value of export products. The significant spike in 2008 could also be due to the reduction in the timber export levy from $3 \%$ to $1.5 \%$ chargeable on all timber exports from Ghana instituted in January 2007 (Forestry Commission (FC), 2007).

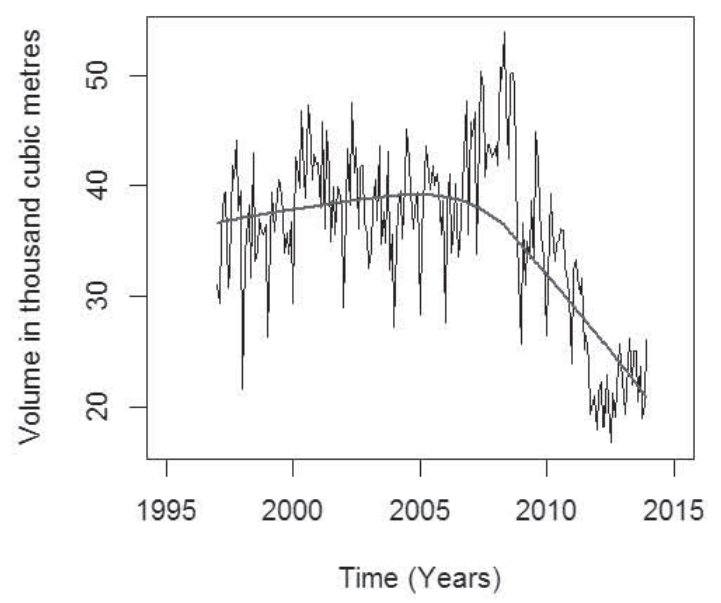

Figure 1. Volume of wood products exported from 1997-2013 
The wood products exported can be categorized into three namely, (1) Primary: Poles, Billets, logs; (2) Secondary: Blockboards, Boules (Air Dried-AD, Kiln Dried-KD), Curls, Veneer (Rotary, Sawn, Curls, Sliced), Layons, Lumber (AD, KD, Overland (OL)), Pegs. Plywood, Sleepers, Kindling and Furniture Parts; and (3) Tertiary: Broomsticks, Dowels, Flooring, Flush doors, Moulding (processed, OL), Powdered Barks and Profile Boards. Secondary products accounted for about $88 \%$ of the total volume of wood products export and $88.7 \%$ of the total export earnings (Figures $2 \& 3$ ).

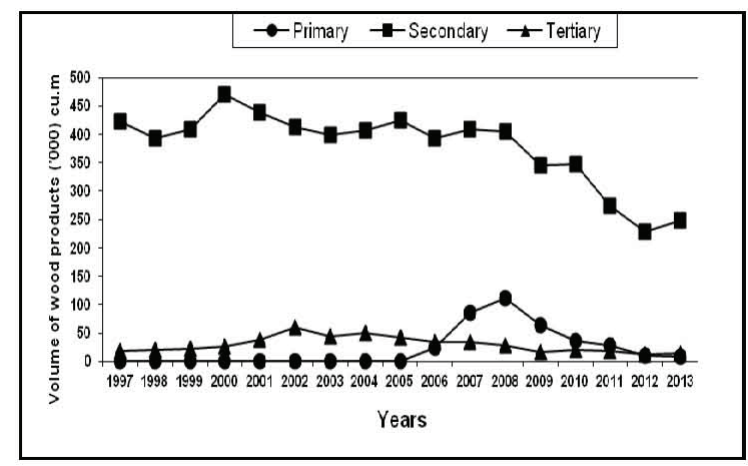

Figure 2. Trends in the volume of wood products export from 1997-2013

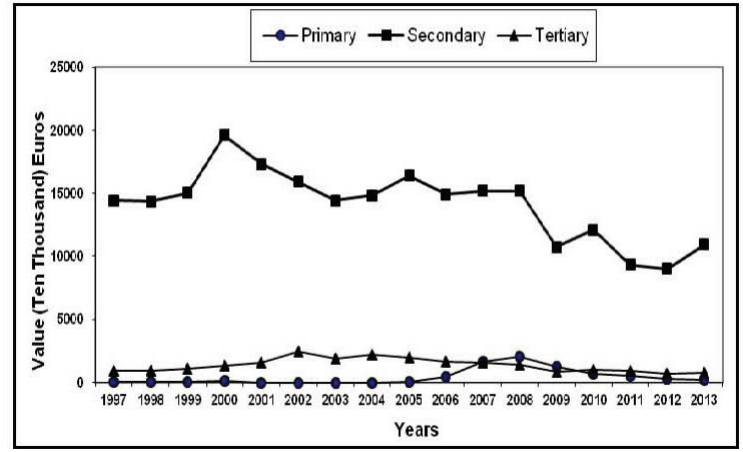

Figure 3. Trends in the value of wood products export from 1997-2013

The top five products namely Lumber (Kiln Dried), Lumber (Air Dried), Plywood (OL), Rotary Veneer and Sliced Veneer, all of which are Secondary products, accounted for $75 \%$ of the total volume and $76.6 \%$ of the total export earnings (Table 1). The products which were least exported during the period under review were Powdered barks, Pegs, Moulding (OL), Sliced veneer (OL) and Sawn veneer. There were no exports of Primary wood products from 2001-2004 (Figure 2). This was due to a total ban on the export of logs imposed in 2000. This move was a strategic management policy by the sector Ministry following the glut in exports of Ghana's logs. The policy was also meant to address some observed malpractices and to check the unbridled felling of timber trees in the country's forests.

Table 1. Volume and value of wood products export from 1997-2013

\begin{tabular}{lcc}
\hline Product & Volume $\left(\mathrm{m}^{3}\right)$ & Value (Euro) \\
\hline Lumber (Kiln Dried) & 1817695.20 & 667705250.20 \\
Lumber (Air Dried) & 1493347.64 & 507587671.50 \\
Plywood (Overland) & 896756.40 & 263557045.60 \\
Rotary Veneer & 715121.18 & 181264976.45 \\
Sliced Veneer & 550491.72 & 451467043.45 \\
All other products & 1829416.49 & 631433594.73 \\
Total & 7302828.63 & 2703015581.94 \\
\hline
\end{tabular}

From 2001-2004 export earnings increased substantially for tertiary products but to a lesser extent for secondary 
products. This could be attributed to the policies and measures which were put in place by the Forestry Commission to promote the export of value-added wood products. One of such policies was the complete ban on unprocessed logs in 1995. Log exports were considered inefficient due to the huge price differentials between logs and other processed timber products. Following this ban, the emphasis of the forest products export sector has been on secondary and tertiary processed wood products. In addition, the introduction of the Woodworking Sector Development Programme (WSDP) which was a Donor Assisted Resource management project implemented from 1998-2002 promoted the increased utilization and value addition of Lesser Used timber Species (LUS) through direct Technical Assistance for the acquisition of kiln drying and value added machinery and equipment. Financial incentives were given to timber companies that exported valued added products of the LUS. Donkor (2003) observed that for Ghana's wood products export to be competitive in the international markets, efforts should be directed towards the production of value-added products instead of primary products that requires high volume but are sold at a lower average value.

The sudden rise in the export of primary wood products (Figure 2) from mid 2006 was due to the granting of permits for the commercial exploitation of plantation timber mainly Teak and Gmelina by Forestry Commission to some companies for export to India and other Far East countries. Plantation Timber Utilization contracts were approved for both government owned and private plantations. By 2007, a bidding process to determine the granting of permits was instituted for all timber exporting companies for the exploitation of plantation timber for export. This accounted for the surge in export volumes of the primary wood products during the period.

\subsection{Export Destinations of Wood Products}

Ghana has been exporting about thirty varieties of wood products to 76 countries worldwide from 1997-2013. Not all the 76 countries have been able to import wood products consistently for all the years in the period under review. The European Union (EU) has been the major destination for Ghana's wood products accounting for $40 \%$ of all wood products export from 2000-2013. However, the market share of the EU is declining, dropping from $57 \%$ in 2000 to $31 \%$ in 2013. Currently, the FLEGT/VPA process, including the Timber Regulation in the EU, demand high quality standards for wood products and the demand for certified wood products is also increasing. The African market is the next highest importer of Ghana's wood products. From 2009-2013, it emerged as the major destination for Ghana's wood products export. This is not surprising as the total consumption of wood in Africa is about 700 million cubic meters $\left(\mathrm{m}^{3}\right)$ per year, with approximately 75 million $\mathrm{m}^{3}$ consumed for industrial wood products and the remaining 625 million $\mathrm{m}^{3}$ consumed for fuel wood (Global Environment Fund (GEF), 2013). Africa accounts for more than one-fifth of the total 3.5 billion $m^{3}$ annual global demand for wood (GEF, 2013). Major Africa destinations for Ghana's wood products are South Africa, Morocco, Cape Verde and the ECOWAS countries mainly, Nigeria, Niger, Benin, Senegal, Burkina Faso, Mali and Togo. The ECOWAS subregion accounted for $1280830 \mathrm{~m}^{3}(84 \%)$ valued at Euros 336.27 million (79\%) of the total African wood exports from Ghana during the period 2000-2013.

The emerging markets in Asia and Far East also contributed $1014590 \mathrm{~m}^{3}$ (17\%) valued at 316.15 million Euros (14\%) of the total wood products export. In 2005 there was sharp increase in both volume and export earnings from Asia and Far East but this dropped in 2006 and then increased steeply in 2007. The volumes and export earnings declined gradually until 2012 and then started to recover again in 2013. This indicates that there is no consistency in the volume of wood products that are exported from Ghana to Asia and Far East (Figures $4 \& 5$ ). The upward and downward movement observed in the export volumes of Ghana's wood products by the Asia/Far East markets from 2005-2010 are perhaps a reflection of the Forestry Commission's intermittent actions necessitated by the need to streamline Teak production and exports to the Asia/Far East markets. Thus, within the period the bidding process for teak production was intermittently suspended and reviewed until it was finally halted when the standing stock of Teak in Ghana's forests was thought to be dwindling, particularly in government plantations. Production from private plantations however continued. 


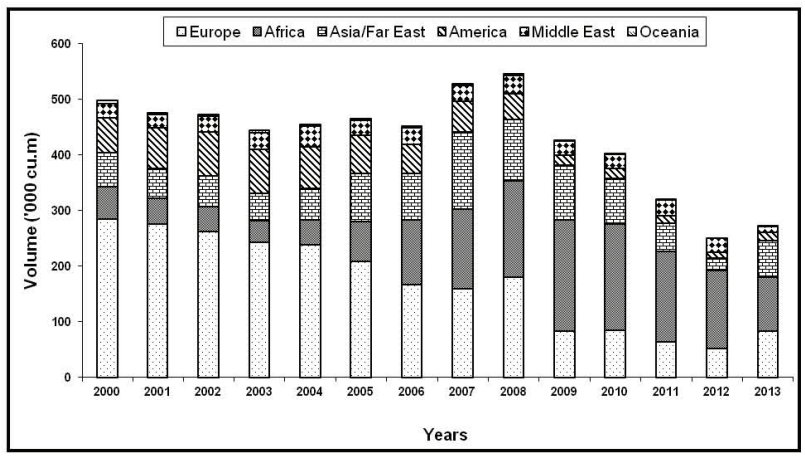

Figure 4. Major markets of Ghana's wood products by volume $\left(\mathrm{m}^{3}\right)$ 2000-2013

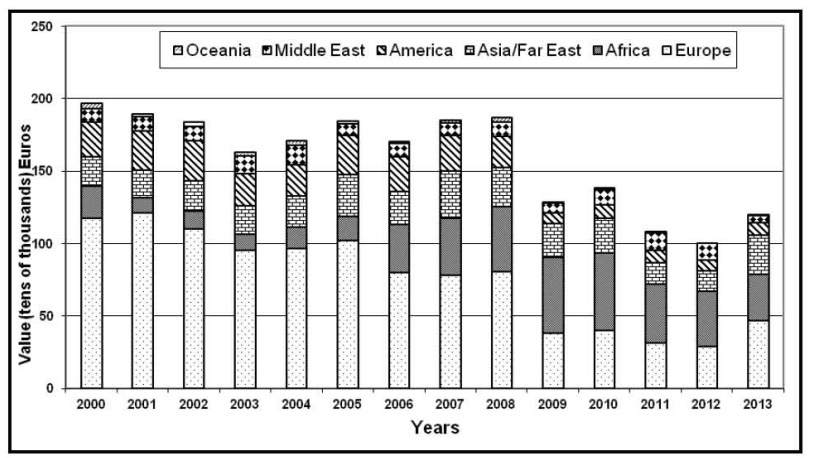

Figure 5. Major markets of Ghana's wood products by value (Euros) 2000-2013

\subsection{Building ARIMA Model for Volume of Wood Products Export Data and Forecasting}

The volume of wood products exported over the period 1997-2013 consists of 204 monthly observations to build a suitable seasonal $\operatorname{ARIMA}(\mathrm{p}, \mathrm{d}, \mathrm{q}) \times(\mathrm{P}, \mathrm{D}, \mathrm{Q})_{12}$ model. A decomposition of the series against time exhibits a trend and a constant seasonal variation over time. The series also has a non-zero mean and a non-constant variance indicating clearly that the underlying series is non-stationary.

\subsection{Test for Stationarity}

The application of Box-Jenkins methodology in building an ARIMA model requires that the series is stationary. Therefore, the process starts with testing the series for stationarity using the Correlogram, performing an Augmented Dickey-Fuller test (ADF) and Kwiatkowski-Phillips-Schmidt-Shin (KPSS) test. The Correlogram indicates that the Autocorrelation Function (ACF) decays slowly to zero as it moves to higher order lags and the Partial Autocorrelation Function (PACF) shows significant spikes at lags 1 and 2 (Figure 6a \& 6b). This indicates that the series is non-stationary. This is re-affirmed from the ADF test and KPSS test (Table 2).

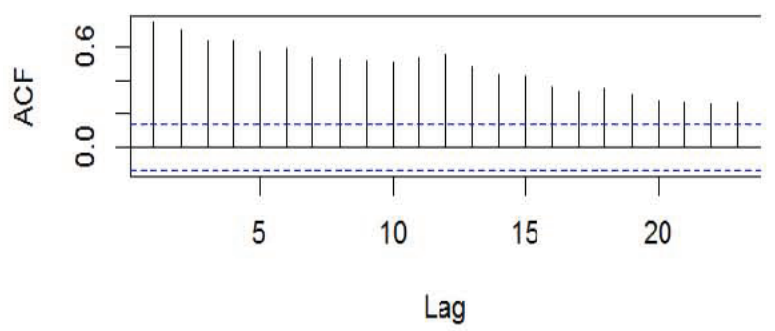

Figure 6a. ACF of the original series 


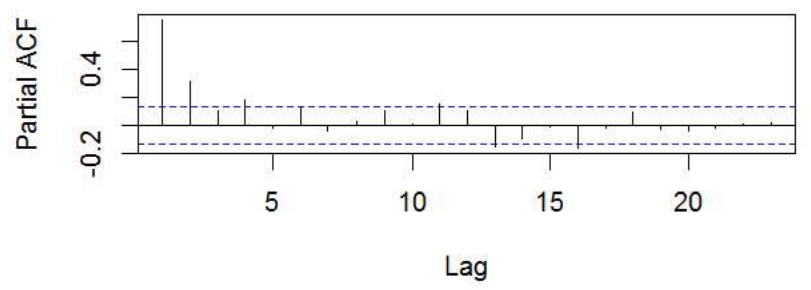

Figure $6 \mathrm{~b}$. PACF of the original series

Table 2. Unit root test and stationary test for the time series data

\begin{tabular}{lccc}
\hline & \multicolumn{3}{c}{ Summary of Test Statistic } \\
\hline Type of test & Test Statistic & Lag Order & P-value \\
\hline KPSS (level) & 1.711 & 3 & 0.01 \\
KPSS (Trend) & 0.7547 & 3 & 0.01 \\
ADF & -2.2998 & 5 & 0.45 \\
\hline
\end{tabular}

The KPSS test the null hypothesis for a level and trend stationary against an alternative of a unit root whiles the ADF test the null hypothesis of a unit root against the alternative of a stationary series. The ADF test failed to reject the null hypothesis at 5\% significance indicating that the series has a unit root ( $p$-value $=0.45)$. The KPSS test also showed a unit root in level $(p$-value $=0.01)$ and trend $(p$-value $=0.01)$ at $5 \%$ significance level. After the series was found to be non stationary through the various tests, a logarithmic transformation was undertaken on the original data to attain stationarity in variance and mean. A first difference and seasonal difference was also performed to eliminate trend and seasonal variation in the series. A plot of the series after taking the logarithmic transformation, first differencing, and seasonal differencing indicated a mean of zero and somehow constant variance (Figure 7).

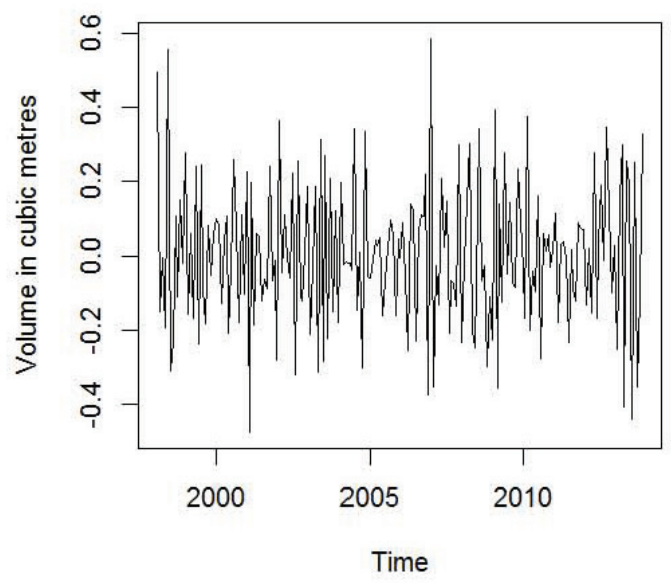

Figure 7. Log transformation, first and seasonal differencing of volume of wood products export from 1997-2013

The unit root test which is a formal method of testing the stationarity of a series is subsequently performed to augment the graphical analysis since ignoring the problem of a unit root will cause an error with the statistical inference (Nelson \& Plosser, 1982).

Table 3. Unit root test and stationary test for the transformed and differenced series

\begin{tabular}{lccc}
\hline & \multicolumn{3}{c}{ Summary of Test Statistic } \\
\hline Type of test & Test Statistic & Lag Order & P-value \\
\hline KPSS (level) & 0.0358 & 3 & 0.10 \\
KPSS (Trend) & 0.0308 & 3 & 0.10 \\
ADF & -6.4039 & 5 & 0.01 \\
\hline
\end{tabular}


As indicated in Table 3, the KPSS test fails to reject the null hypothesis of both level and trend stationary at 5\% significance level whiles the ADF test rejects the null hypothesis of a unit root. It can therefore be concluded that the transformed and differenced time series data is now stationary. Hence, an ARIMA(p, 1, q) (P, 1, Q) 12 model could be identified for the first difference and seasonal difference of the volume of wood products export data.

\subsection{Model Identification}

The $p, q, P$ and $Q$ parameters need to be identified for the model. Visual inspection of the correlogram (Figure 8 a) indicates that the autocorrelation at lag 1 exceed the significance bounds $(-0.14,0.14)$ and then tails off to zero till it reaches lag 11. The autocorrelation at lags 11 and 13 also exceeds the significance bounds and they are all positive (lag 11: 0.27, lag 13:0.23) and then tails off to zero again.

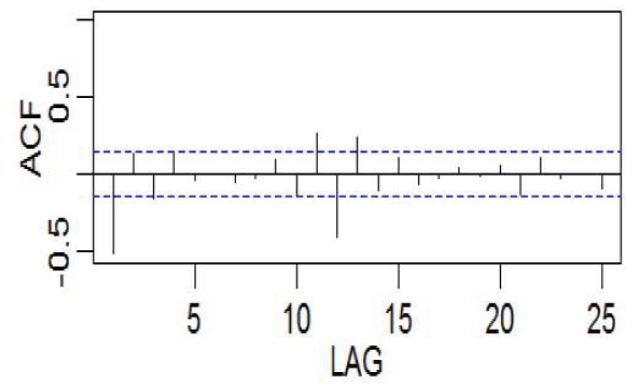

Figure 8a. ACF plot

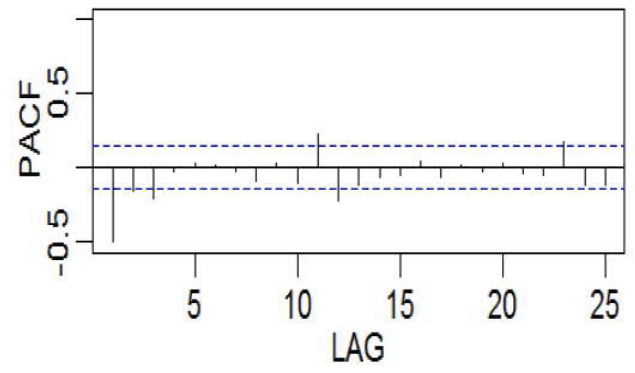

Figure 8b. PACF plot

From the partial autocorrelogram (Figure 8b), we see that the partial autocorrelation at lags 1, 2 and 3 are all negative and exceeds the significance bounds (lag 1:-0.51, lag2:-0.16, lag3: -0.22). The partial autocorrelations tail off to zero after lag 3. The partial autocorrelation at lags 11,12 and 23 also exceeds the significance bounds. Since the correlogram tails off to zero after lag 1 , and the partial correlogram is zero after lag 3 , an ARIMA(3, 1, $1)$ is suggested for the non-seasonal time series and an $\operatorname{ARIMA}(0,1,1)$ for the seasonal time series because there is exponential decay at lag 12 in the ACF plot. The tentative model is therefore ARIMA $(3,1,1)(0,1,1)_{12}$. The following models are also suggested. $\operatorname{ARIMA}(3,1,1)(1,1,1)_{12}$ and $\operatorname{ARIMA}(3,1,0)(0,1,1)_{12}$. The procedure for choosing the most suitable model relies on choosing the model with the minimum Akaike Information Criterion (AIC), Akaike Information Criterion corrected (AICc) and Bayesian Information Criterion (BIC).

\subsection{Estimation of Model Parameters}

Tables 4 and 5 show that $\operatorname{ARIMA}(3,1,0)(0,1,1)_{12}$ is the best model because it has the least AIC, AICc and BIC. In addition coefficients of the model parameters are significantly different from 0 at $5 \%$ significance level. The fitted model is thus

$$
\left(1+.62_{(.07)} B+.33_{(.08)} B^{2}+.25_{(.07)} B^{3}\right)\left(1-B^{12}\right)(1-B) \hat{x}_{t}=\hat{w}_{t}-B^{12} \hat{w}_{t}
$$

with $\hat{\sigma}_{w}^{2}=0.01333$.

Table 4. Values of AIC, AICc and BIC criteria for ARIMA models

\begin{tabular}{lccc}
\hline Model & AIC & AICc & BIC \\
\hline ARIMA $(3,1,1)(0,1,1)_{12}$ & -234.39 & -233.78 & -211.62 \\
ARIMA $(3,1,1)(1,1,1)_{12}$ & -236.33 & -235.88 & -216.82 \\
ARIMA $(3,1,0)(0,1,1)_{12}$ & -238.17 & -237.85 & -221.91 \\
\hline
\end{tabular}


Table 5. Model characteristics

\begin{tabular}{lcccc}
\hline Model & Parameter & Parameter value & Standard Error & t-value \\
\hline ARIMA $(3,1,1)(0,1,1)_{12}$ & $\phi_{1}$ & -0.4632 & 0.4212 & -1.09972 \\
& $\phi_{2}$ & -0.2385 & 0.2596 & -0.91872 \\
& $\phi_{3}$ & -0.2179 & 0.1195 & -1.82343 \\
& $\theta_{1}$ & -0.1607 & 0.4394 & -0.36573 \\
& $\Theta_{1}$ & -0.0194 & 0.0822 & -0.23601 \\
\hline ARIMA $(3,1,1)(1,1,1)_{12}$ & $\phi_{1}$ & -0.4574 & 0.4146 & -1.10323 \\
& $\phi_{2}$ & -0.2341 & 0.2565 & -0.91267 \\
& $\phi_{3}$ & -0.2156 & 0.1188 & -1.81481 \\
& $\theta_{1}$ & -0.1687 & 0.4315 & -0.39096 \\
& $\Phi_{1}$ & -1 & 0.0738 & -13.5501 \\
& $\Theta_{1}$ & -0.4574 & 0.4146 & -1.10323 \\
\hline ARIMA $(3,1,0)(0,1,1)_{12}$ & $\phi_{1}$ & -0.6159 & 0.0714 & -8.62605 \\
& $\phi_{2}$ & -0.3265 & 0.0818 & -3.99144 \\
& $\phi_{3}$ & -0.2474 & 0.0723 & -3.42185 \\
& $\Theta_{1}$ & -1 & 0.0742 & -13.4771 \\
\hline
\end{tabular}

\subsection{Diagnostics Checking of Estimated Residuals}

The model adequacy is checked to determine if the model fits the data well so that empirical conclusions can be drawn. This is achieved by performing a Ljung-Box Test coupled with ACF plot of the residuals and a normal Q-Q plot as reported in Figure 9. Inspection of the time plot of the standardized residuals in Figure 9 shows no obvious patterns. The ACF of the standardized residuals show no apparent departure from the model assumptions and the Q-Statistic is never significant at lags 1 to 35 . The normal Q-Q plot of the residuals is approximately normal although both ends tail off a bit. The p-values of the Ljung-Box statistic are all quite large (greater than the chosen $\alpha$-level of 0.05 ), thus we fail to reject the null hypothesis that the residuals are uncorrelated. This indicates that the residuals of the fitted $\operatorname{ARIMA}(3,1,0)(0,1,1)_{12}$ model are white noise, fits the data quite well and could be used to forecast the volume of wood products export. Table 6 represents the forecasting results of the volume of wood products export over the period 2014-2015.

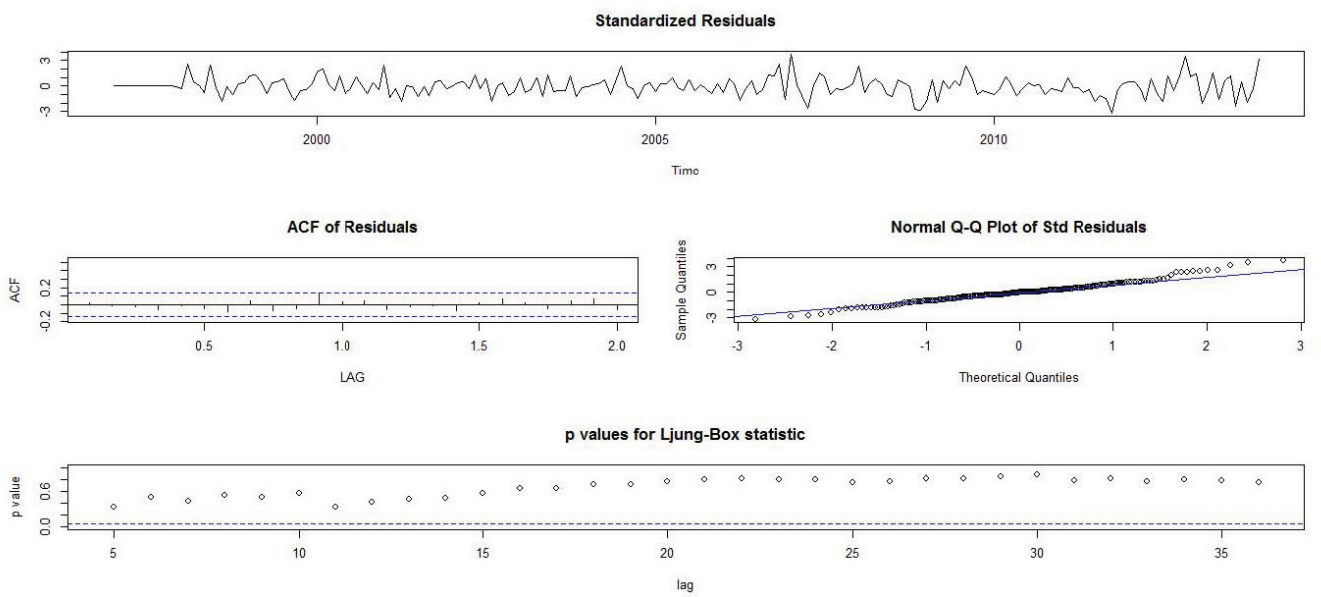

Figure 9. Residual plot for $\operatorname{ARIMA}(3,1,0)(0,1,1)_{12}$ 
Table 6. Forecasting results of the volume of wood products export over the period 2014-2015 using ARIMA(3, 1, $0)(0,1,1)_{12}$

\begin{tabular}{ccccc}
\hline Year & Month & Forecast $\left(\mathrm{m}^{3}\right)$ & Lower Limit (95\% Limit) & Upper Limit (95\% Limit) \\
\hline 2014 & Jan & 18660.10 & 16506.32 & 20815.51 \\
& Feb & 21628.80 & 18975.32 & 24326.81 \\
& Mar & 23762.55 & 20641.53 & 26993.15 \\
& Apr & 23706.20 & 20463.91 & 27098.47 \\
& May & 23904.78 & 20360.90 & 27693.76 \\
& Jun & 24370.80 & 20586.82 & 28468.17 \\
& Jul & 22484.66 & 18830.22 & 26492.73 \\
& Aug & 23689.05 & 19693.69 & 28117.56 \\
& Sep & 23529.94 & 19402.28 & 28157.77 \\
& Oct & 23065.12 & 18881.73 & 27802.20 \\
& Nov & 22084.93 & 17949.98 & 26812.52 \\
& Dec & 22225.90 & 17943.24 & 27166.10 \\
\hline 2015 & Jan & 18140.04 & 14520.36 & 22361.90 \\
& Feb & 21520.06 & 17106.75 & 26713.39 \\
& Mar & 23701.75 & 18712.20 & 29624.12 \\
& Apr & 22634.47 & 17753.78 & 28474.69 \\
& May & 23293.60 & 18149.97 & 29498.95 \\
& Jun & 23774.09 & 18408.21 & 30297.43 \\
& Jul & 22010.56 & 16937.74 & 28223.85 \\
& Aug & 23015.32 & 17605.22 & 29689.44 \\
Sep & 22934.81 & 17440.14 & 29761.14 \\
Oct & 22472.96 & 16991.19 & 29329.61 \\
Nov & 21540.55 & 16194.63 & 28271.70 \\
Dec & 21649.46 & 16187.05 & 28571.67 \\
\hline
\end{tabular}

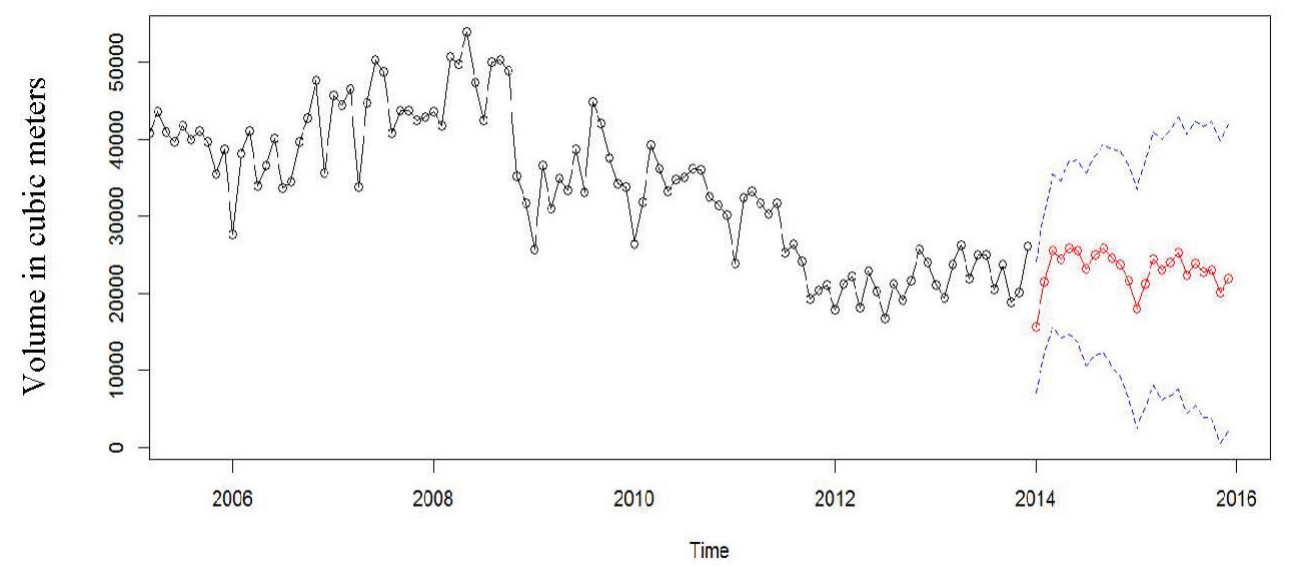

Figure 10. Forecast and confidence intervals of the volume of wood products export from 2014-2015 using $\operatorname{ARIMA}(3,1,0)(0,1,1)_{12}$

From the forecasted values, the months of January and June will experience the lowest and highest volume of wood products export respectively.

\section{Conclusion}

The developed model for the volume of wood products export was found to be $\operatorname{ARIMA}(3,1,0)(0,1,1)_{12}$. This produces a good forecast in the export of the volume $\left(\mathrm{m}^{3}\right)$ of wood products from Ghana to the international markets. The forecast results show that the volume of wood products to be exported in 2014 and 2015 are 273 $112.83 \mathrm{~m}^{3}$ and $266687.67 \mathrm{~m}^{3}$ respectively. These figures do not show much difference from the current pattern of wood products export. Thus, unless the timber resource base is significantly increased Ghana would not be able 
to meet the future export demand for wood products under a scenario of increasing international and domestic demand for wood products. These forecast values will enable the timber industry to keep comprehensive details on the quantity of wood products to be exported over a period of time. This could also help avoid financial losses that may result from poor decision making, improve the efficiency in planning and utilize timber resources in an efficient manner. This study is based on the assumption that related events will not drastically change the statistics. The developed model should be updated from time to time with incorporation of current data.

\section{Acknowledgements}

The authors wish to thank Mr. Godfried Amankwah of the research and statistics unit of TIDD, Ghana for his immense contribution. We also thank Dr. Lawrence Damnyag and Mr. Kwame A. Oduro all of CSIR-Forestry Research Institute of Ghana for their comments. We wish to thank the anonymous reviewers for their comments and suggestions that helped to improve the paper.

\section{References}

Adams, M. (2002). Grow the markets before growing the wood. Tropical Forest Update, 12, 4.

Box, G. E. P., \& Jenkins, G. M. (1970). Time series analysis: Forecasting and control. San Francisco, Holden Day.

Chatfield, C. (2004). The analysis of time series, an introduction (6th ed.). New York: Chapman \& Hall/CRC.

Citifmonline. (2007). Revenue from timber exports decline. Retrieved May 2, 2014 from http://www.allghanadata.com

Daily Guide. (2012). 60 Timber companies collapse, 30,000 jobs lost. Retrieved May 29, 2014 from http://www.viasat1.com.gh/v1/vnews/business.php?postId=398

Donkor, B. N. (2003). Evaluation of government interventions in Ghana's forest product trade: A post-intervention impact assessment and perceptions of marketing implications (Doctoral Dissertation, Louisiana State University, Baton Rouge, School of Renewable Natural Resources). Retrieved from http://etd.lsu.edu/docs/available/ etd-0822103-173901/

Food and Agriculture Organization. (2005). Status of Tropical Forest Management. Food and Agriculture Organization of the United Nations, Rome.

Food and Agriculture Organization. (2010). Global Forest Resources Assessment. FAO, Rome.

Forestry Commission. (2007). Review of Timber Export Levy. FC/D.01/Sf.7/V.3/33

Forest Investment Plan. (2012). Ghana Investment Plan for the Forest Investment Program (FIP). Ministry of Lands and Natural Resources, Ghana.

Forestry Outlook Study for Africa. (2001). Forestry Sector Outlook Studies-FOSA/WP/12. Ministry of Land and Forestry. Country report, Ghana.

Global Environment Fund. (2013). Africa will import and not export wood. Retrieved May 24, 2014 from http://www.globalenvironmentfund.com/wp-content/uploads/2013/05/GEF_Africa-will-Import-not-ExportWood1.pdf

Gershenfeld, N. (1999). The nature of mathematical modeling. Cambridge University Press.

Ghana-RPP. (2010). Readiness Preparation Proposal for Ghana. Revised proposal submitted to Forest Carbon Partnership Facility (FCPF). Accra, Ghana.

Hansen, C. P., Damnyang, L., Obiri, B. D., \& Carlsen, K. (2012). Revisiting illegal logging and the size of the domestic timber market: The case of Ghana. International Forestry Review, 14(1), 1-11. http://dx.doi.org/10.1505/146554812799973181

Marfo, E. (2010). Chainsaw milling in Ghana: Context, drivers and impact. Tropenbos International, Wageningen, the Netherlands. ISBN: 978-90-5113-092-8.

Nelson, C. R., \& Plosser, C. I. (1982). Trends and random walks in macroeconomic time series: some evidence and implications. J. Monetary Econ., 10, 139-62. http://dx.doi.org/10.1016/0304-3932(82)90012-5

Oduro, K. A., Duah-Gyamfi, A., Acquah, S. B., \& Agyeman, V. K. (2012). Ghana forest and wildlife handbook. 
Forestry Commission, Accra, Ghana, ISBN 978-9988-1-4365-7.

Oduro, K. A., Mohren, G. M. J., Affum-Baffoe, K., \& Kyereh, B. (2014). Trends in timber production systems in the high forest zone of Ghana. International Forestry Review, 16(3), $289-300$. http://dx.doi.org/10.1505/146554814812572458

Owusu, J. H. (2001). Determinants of export-oriented industrial output in Ghana: the case of formal wood processing in an era of economic recovery. The Journal of Modern African Studies, 39, 51-80. http://dx.doi.org/10.1017/S0022278X01003524

Shumway, R. H. (1988). Applied statistical time series analysis. Englewood Cliffs, New Jersey: Prentice Hall.

Timber Industry Development Division. (2010). Report of Export Permits December 2010. Timber Industry Development Division, Forestry Commission, Takoradi.

Timber Industry Development Division. (2012). Timber Industry Development Division. Export of wood products report, Ghana.

\section{Copyrights}

Copyright for this article is retained by the author(s), with first publication rights granted to the journal.

This is an open-access article distributed under the terms and conditions of the Creative Commons Attribution license (http://creativecommons.org/licenses/by/3.0/). 